\title{
Indoor Household Particulate Matter Measurements Using a Network of Low-cost Sensors
}

\author{
Shruti Hegde ${ }^{1 *}$, Kyeong T. Min ${ }^{2}$, James Moore ${ }^{3}$, Philip Lundrigan ${ }^{3}$, Neal Patwari ${ }^{2}$, \\ Scott Collingwood ${ }^{4}$, Alfred Balch ${ }^{4}$, Kerry E. Kelly ${ }^{1}$ \\ ${ }^{1}$ University of Utah, Department of Chemical Engineering, Salt Lake City, UT 84112, USA \\ ${ }^{2}$ University of Utah, Department of Electrical and Computer Engineering, Salt Lake City, UT 84112, USA \\ ${ }^{3}$ School of Computing, University of Utah, Salt Lake City, UT 84112, USA \\ ${ }^{4}$ Department of Pediatrics, University of Utah, Salt Lake City, UT 84112, USA
}

\begin{abstract}
The World Health Organization estimates that 4.3 million deaths globally in 2012 were attributable to household air pollution, of which particulate matter (PM) with a diameter of $2.5 \mu \mathrm{m}$ or less $\left(\mathrm{PM}_{2.5}\right)$ is a significant contributor. When integrated with a wireless network, low-cost PM measurements potentially provide personalized information on indoor concentrations in real time so that individuals can take action. The objectives of this study were to (1) deploy a network of research-grade instruments and low-cost sensors in a home environment and evaluate the performance, (2) characterize activities and conditions that increase PM concentrations, and (3) identify how these activities affect the PM levels in different rooms of a home. The wireless sensor network included low-cost PM sensors, a gateway, and a database for storing data. Based on the commercially available Dylos DC1100 Pro (Utah Modified Dylos Sensor) and Plantower PMS sensor (AirU), the low-cost sensors were compared to three research-grade instruments - the GRIMM, DustTrak, and MiniVol-in two households in Salt Lake City during summer and winter, with the results suggesting that the low-cost sensors agreed well with the DustTrak. Of the activities, frying food and spraying aerosol products generated the largest increase in PM, both in the room of the activity (the kitchen and bedroom, respectively) and the adjacent rooms. High outdoor PM concentrations during a cold air pool episode also caused indoor levels to rise. In addition, different PM sources triggered different sensor responses. Consequently, obtaining accurate estimates of the mass concentration in an indoor environment, with its wide variety of PM sources, is challenging. However, low-cost PM sensors can be incorporated into an indoor air-quality measurement network to help individuals manage their personal exposure.
\end{abstract}

Keywords: Indoor air; Particulate matter; Sensor network; Low-cost particulate matter sensor; Cold air pool.

\section{INTRODUCTION}

The World Health Organization (WHO) estimates that 4.3 million people die annually from household air pollutant exposure (World Health Organization, 2014), and particulate matter (PM) is one key driver of air pollution's adverse health effects. Particles with an aerodynamic diameter of $2.5 \mu \mathrm{m}$ or smaller $\left(\mathrm{PM}_{2.5}\right)$ are a particular concern because these particles can penetrate deeply into the lungs and can cause serious health effects, including cardiac arrhythmia, coronary heart disease and premature death (Sorensen et al., 2003; Brook et al., 2010; Anderson et al., 2012). Consequently, the WHO and government organizations have set ambient

\footnotetext{
* Corresponding author.

Tel.: 1-385-282-9438

E-mail address: shruti.hegde@utah.edu
}

air quality standards for $\mathrm{PM}_{2.5}$. For example, the U.S. National Ambient Air Quality Standards (NAAQS) for $\mathrm{PM}_{2.5}$ are $35 \mu \mathrm{g} \mathrm{m}^{-3}$ (24 hour) and $12 \mu \mathrm{g} \mathrm{m}^{-3}$ (annual average) (U.S. Environmental Protection Agency, 2014). The WHO $\mathrm{PM}_{2.5}$ standards are $25 \mathrm{\mu g} \mathrm{m}^{-3}$ (24-hour mean) and $10 \mu \mathrm{g} \mathrm{m}^{-3}$ (annual average) (World Health Organization, 2006). Indoor levels of PM are significant contributors to an individual's exposure because people typically spend up to $90 \%$ of their time indoors (Spengler and Sexton, 1983; Zhang and Smith, 2003; Zhu et al., 2015), and PM concentrations indoors can surpass outdoor levels (Klepeis et al., 2001). In addition, individuals with chronic health conditions often spend a greater portion of their time indoors and are more vulnerable to the adverse impacts of indoor PM exposure. Sources of indoor PM include aerosol sprays, cooking, burning candles or heating/cooking with solid fuel, inadequately tuned gas stoves and furnaces, pets, dust mites, cleaning and tobacco smoking. In addition, indoor air is also affected by infiltration of outdoor air (Goyal and Kumar, 2013). Indoor 
PM concentrations can be affected by infiltration of outdoor air. Depending on the outdoor PM levels, this infiltration can result in increasing or decreasing indoor PM levels (Morawska et al., 2001; Kumar and Morawska, 2013).

Numerous studies have measured PM concentration indoors by pulling air through a size-selective inlet and collecting PM on a substrate/filter that is subsequently weighed (Braniš et al., 2005; Fromme et al., 2007; Hering et al., 2007; Fromme et al., 2008; Braniš et al., 2009) or have used passive samplers that rely on particle settling onto a substrate that is subsequently weighed (Amaral et al., 2015; Bo et al., 2017). However, these methods suffer from limitations. First, the substrate/filter measurements are integrated over time (from several hours to several days) and do not capture temporal variations in particle concentration. Second, they are timeconsuming to collect and analyze, and results may not be available for several days after sampling is complete (Amaral et al., 2015; Kumar et al., 2016). Third, many of these samplers require a pump, and are bulky and noisy for indoor use. For passive samples that require long sampling times, there is a risk of loss of sampled material (Kumar et al., 2016). Research-grade instruments based on optical detection methods have also been used to measure indoor PM levels (Amaral et al., 2015). They can provide accurate, timeresolved, rapid PM measurements, but the cost for these ranges from $\$ 5,000$ to $\$ 20,000$, making them too expensive to deploy many instruments in multiple indoor environments or for use in population-based studies.

Commercially available low-cost PM sensors are becoming more widely available, and with their rapid response they offer the potential for gathering large quantities of high-resolution spatio-temporal air-quality information in indoor and outdoor environments (Kumar et al., 2016). They typically use light scattering to estimate PM concentrations, and light scattering is a common measurement strategy for researchgrade PM monitors. The cheapest PM sensors cost less than \$20. Examples include the Shinyei PPD42NS Dust Sensor (Shinyei Corp.), Sharp GP2Y1010 (Sharp Corp.), Plantower PMS series (Plantower Technology), and Honeywell HPM series particle sensor (Honeywell Inc.). These sensors require an interface with an external microprocessor and either a display or a way to transmit data to the user. Adding these features can significantly increase the price, above $\$ 100$ (e.g., Alphasense OPC from Alphasense). However, once integrated with a microcontroller, these types of sensors are well suited for deployment in a sensor network. Slightly more expensive sensors, costing between $\$ 200$ and $\$ 500$, push their data to the cloud for viewing through a user interface (e.g., Air Quality Egg from Wicked Device, LLC) or an on-screen display (e.g., Dylos monitors from Dylos Corporation or Speck from CREATE Lab, Carnegie Mellon University) (Jovašević-Stojanović et al., 2015). These more expensive sensors may require modifications to allow integration with a sensor network.

However, low-cost PM sensors have their drawbacks. They are not as accurate as gravimetric sampling methods (Dacunto et al., 2013) or reference PM instruments (Manikonda et al., 2016). These sensors can also be affected by humidity (Wang et al., 2015), temperature (Gao et al., 2015) and the same set of sensors can perform inconsistently (Gao et al., 2015; Zikova et al., 2017). In addition, most sensors lack guidance on deployment and calibration data under different conditions. Furthermore, light-scattering PM measurements require regular calibration and an appropriate correction factor (CF) for the aerosol types (Dacunto et al., 2015) and environmental conditions under which the sensors are operating (Kelly et al., 2017; Sayahi et al., 2019). Low-cost PM sensors may be more sensitive to particle properties than research-grade monitors (Kelly et al., 2017). Also, laboratory performance observed by these sensors are often not reproducible under field conditions, where they exhibit lower correlations with reference instrumentation (Castell et al., 2017). In spite of these limitations, the sensors can provide valuable information on relative levels of $\mathrm{PM}$, aid in estimating personal exposure and help identify strategies for reducing these exposure levels. For example, real-time monitoring can aid health researchers in determining which measures, e.g., maximum 10-minute concentration, are most relevant to health outcomes. They are also valuable for development of intervention measures and for meaningful public health metrics, which are accessible to the general public.

Several studies have evaluated the performance of lowcost optical PM sensors in laboratory settings and found moderate to strong correlations with reference instruments, which include Dylos vs. TSI DustTrak $\left(\mathrm{R}^{2}>0.81\right.$; Northcross et al., 2013), Dylos vs. GRIMM ( $\mathrm{R}^{2}>0.86$; Vercellino et al., 2018), and Shinyei PPD42NS vs. TSI Aerodynamic Particle Sizer Spectrometer ( $\mathrm{R}^{2}>0.66$; Austin et al., 2015). Wang et al. (2015) used the TSI SidePak AM510 and a TSI Scanning Mobility Particle Sizer to evaluate sensor performance and found $\mathrm{R}^{2}>0.78$ for the Shinyei PPD42NS, Samyoung DSM501A, and Sharp GP2Y1010AU0F. Manikonda et al. (2016) evaluated the performance of four low-cost PM monitors (Speck, Dylos, TSI AirAssure, and UB AirSense) against co-located reference instruments (Grimm 1.109, TSI APS 3321 and TSI Fast Mobility Particle Sizer 3091) in a laboratory chamber and found $\mathrm{R}^{2}>0.85$ between the four monitors and APS 3321.

Outdoor studies have also found moderate to strong correlations. For example, Holstius et al. (2014) compared Shinyei performance with a Federal Equivalent Method (FEM) beta-attenuation monitor (BAM) 1020, a Grimm 1.108 and a DustTrak $\left(\mathrm{R}^{2}>0.6\right)$. Gao et al. (2015) studied a network of Shinyei PPD42NS sensors in an urban environment and found strong correlations $\left(\mathrm{R}^{2}>0.87\right)$ between the DustTrak and Met One BAM but only a moderate correlation with mass-based measurements $\left(\mathrm{R}^{2}>0.5\right)$.

A few studies have deployed low-cost PM sensors in indoor environments, some to evaluate performance and others to understand events that affect indoor air quality. Zikova et al. (2017) evaluated sixty-six Speck monitors collocated with a Grimm 1.109. They found a poor correlation during indoor measurements $\left(\mathrm{R}^{2}=0.2-0.3\right)$, but when the measurements were divided into combustion and non-combustion particles, the $\mathrm{R}^{2}$ rose to 0.5 . Patel et al. (2017) deployed a network of five Sharp GP2Y1010AU0F sensors in two different homes to measure PM levels from solid-fuel cookstoves. They found reasonably good correlation $\left(\mathrm{R}^{2}=0.713\right)$ between the 
Sharp sensors collocated with a TSI SidePak AM150. Weekly et al. (2013) designed a wireless PM sensor network consisting of five Samyoung DSM501A, three Shinyei PPD20V sensors and Met One GT-526S laser particle counter to infer resuspension of coarse $(\geq 2.5 \mu \mathrm{m})$ particles caused by movement of occupants. Li et al. (2017) used a wireless network of low-cost sensors (Sharp GP2Y1010AU0F) in a woodworking shop to develop an estimate of worker PM exposure. Jeon et al. (2018) proposed an IoT-based occupancy detection system in indoor environments using a low-cost PM sensor, SEN0177.

The objective of this study was to deploy a wireless PM sensor network in two home environments, evaluate sensor performance, characterize activities (i.e., cooking, spraying aerosol products, burning a candle and cleaning) that affect indoor air quality by household room, identify conditions that affect PM concentrations, and identify how these activities affect different rooms in a home.

\section{MATERIAL AND METHODS}

\section{Study Locations and Measurements}

This study was performed in two homes in two different seasons, summer and winter (Fig. S1). The residents of these two homes volunteered to host the sensors, and they kept a logbook where they manually recorded activities that could generate PM (i.e., cooking, candle burning, etc.). All sensors were placed on a table approximately $0.75-0.80 \mathrm{~m}$ above ground and at least $0.3 \mathrm{~m}$ away from the wall. The first study was conducted between $19^{\text {th }}$ May to $19^{\text {th }}$ July 2016 in a twostory home with a finished basement in Cottonwood Heights, Utah (Home I). A finished basement has been outfitted in a manner making it suitable as a living space. In this study, the occupants were using the finished basement as a living area. The following analyses focus on one calibration week $\left(20^{\text {th }}\right.$ $25^{\text {th }}$ May) (Table S1) and one week of deployment when events are annotated, from $1^{\text {st }}$ to $7^{\text {th }}$ June. This home built in 2002 was located in a suburban, residential area, near the I-215 interstate (364 m away) in Utah's Wasatch Front (with a population of 2.21 million; U.S. Department of Commerce, 2010). The home was 3300 sq. ft. with 1650 sq. ft. in the basement and 1650 sq. $\mathrm{ft}$. on the first floor. This home was located $16 \mathrm{~km}$ from the nearest state air-quality monitoring station (Hawthorne). Although some sensors were placed in the basement, there were no annotated events, and the basement was not used for this study. The study in Home II (built in 1942 ) occurred from $16^{\text {th }}$ January to $16^{\text {th }}$ February 2017 in a two-story house in an urban, residential neighborhood of Salt Lake City, Utah, with a calibration study from $15^{\text {th }}-21^{\text {st }}$ October 2016 (Table S1). The home was 1500 sq. ft. with a finished basement. The calibration in Home II was conducted in the basement, and the basement was not used for the later part of the study. This home was located $8 \mathrm{~km}$ from the nearest state air-quality monitoring station (Rose Park).

At each of the homes, a 1-week calibration experiment was performed to assess sensor precision and accuracy by collocating the low-cost sensors with four research-grade PM instruments (two GRIMM 1.109s from GRIMM Aerosol Technik, GmbH; one DustTrak II aerosol monitor from TSI
Inc.; and one filter-based measurement, Airmetrics MiniVol) (Table 1). In Home I, ten Utah Modified Dylos DC1100 Pro sensors (UMDSs) were placed alongside four custom AirU sensors for comparison, and in Home II, four UMDSs were deployed. The state of the doors in each home can affect PM levels and the time required for PM levels to change. During the calibration period, doors were closed, but during the remainder of the study the occupants behaved normally, with no control on the state of the door. After the calibration week, sensors were distributed throughout the home and placed outside the home (locations shown in Fig. S1). The modifications to the Dylos and the AirU sensors are described below.

The GRIMM 1.109 continuously measures particle count and mass distribution by light scattering over the size range of $0.25-32 \mu \mathrm{m}$ in 31 class sizes. The signal from the scattered light is then classified by size and count, and these counts are converted to mass concentrations (Peters et al., 2006). During this study, only the GRIMM's $\mathrm{PM}_{2.5}$ concentrations were used. The DustTrak II Aerosol Monitor 8530 (TSI) is a light-scattering laser photometer, which measures mass concentration $\left(\mathrm{PM}_{1}, \mathrm{PM}_{2.5}\right.$ or $\left.\mathrm{PM}_{10}\right)$ with a size-selective inlet (Alvarado et al., 2015). During this study, the DustTrak II operated with the $\mathrm{PM}_{2.5}$ inlet. The Airmetrics MiniVol is a portable air sampler that was equipped with a size-selective $\mathrm{PM}_{2.5}$ inlet and a $47 \mathrm{~mm}$ Whatman filter (pore size $0.2 \mu \mathrm{m}$ ). These filters were replaced every week during indoor testing, and the difference in weight along with the flow rate provided an integrated mass concentration and allowed for mass adjustment of the GRIMM and DustTrak concentrations.

\section{Sensor and Network Description}

The AirU, developed at the University of Utah, consists of a small custom printed circuit board with a Plantower PMS3003 particle sensor, Bosch BMP180 (temperature, pressure and altitude), an SGX SensorTech MiCS-4514 (CO and $\mathrm{NO}_{2}$ ), an Aosong Electronics DHT22 (temperature and humidity) and an Adafruit Ultimate GPS chip all interfaced with a custom printed circuit board and a Beaglebone Black (BBB). The component costs of the AirU are approximately $\$ 175$. The Plantower PMS sensor reports $\mathrm{PM}_{1}, \mathrm{PM}_{2.5}$ and $\mathrm{PM}_{10}$ concentrations $\left(\mu \mathrm{g} \mathrm{m}^{-3}\right)$ every 60 seconds. This study focused on the AirU's $\mathrm{PM}_{2.5}$ measurements. The AirU can store up to $500 \mathrm{MB}$ of data to an onboard microSD card or it can send readings directly through our gateway to a database (discussed below). This Plantower PMS sensor is described in detail in Kelly et al. (2017), and its $\mathrm{PM}_{2.5}$ concentration correlated well with Federal Reference Method (FRM) $\mathrm{PM}_{2.5}$ concentrations during several winter clean air and cold air pools (CAPs; $\mathrm{R}^{2}>0.88$ ) and with research-grade instruments exposed to alumina oxide particles in a wind tunnel $\left(\mathrm{R}^{2}>\right.$ 0.83). The Plantower PMS sensors were also evaluated by the South Coast Air Quality Management District (SCAQMD) and correlated well with an FEM $\left(\mathrm{R}^{2}>0.93\right)$.

Each UMDS includes a Dylos DC1100 Pro Air Quality Monitor (Dylos Inc., Riverside, California, USA). The UMDS detects PM concentrations in two size ranges: small (2.5 $\mu \mathrm{m}$ and less) and large (10 $\mu \mathrm{m}$ and greater) particles. This study estimated $\mathrm{PM}_{2.5}$ counts as the UMDS small count 


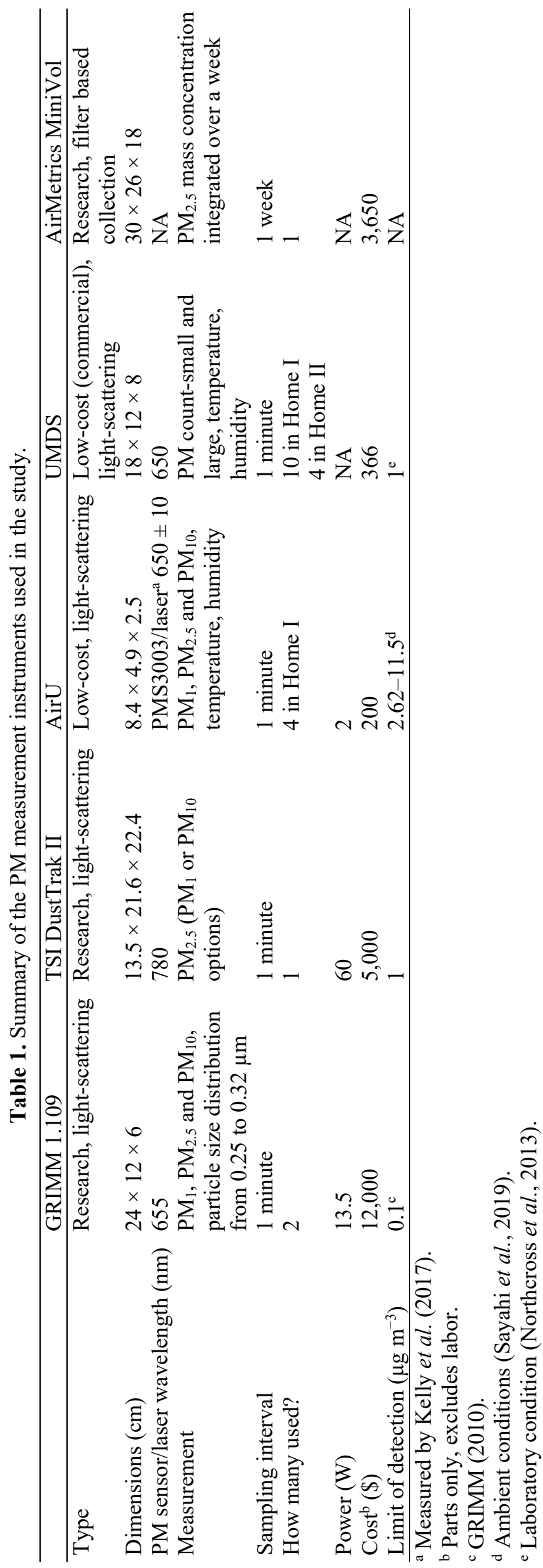

minus the large count. The Dylos sensor was modified to allow networking capabilities. This modification included adding a BBB microprocessor unit with a Wi-Fi module, a compact USB Wi-Fi Adapter with 4" Antenna (UWN200), an SHT21 relative humidity and temperature sensor and an RGB LCD display. The BBB collects all sensor data, displays information (temperature, humidity, small and large particle count) to the RGB LCD display, and transmits data to the cloud server via our gateway. Data from the sensors are also stored on a microSD card so that no data is lost if power is lost to the sensor.

Our in-home sensor network architecture consists of three components - the sensors, a gateway, and database. The data from all low-cost sensors were collected using a gateway, which can support various wireless protocols like BLE (Bluetooth Low Energy), Wi-Fi, and ZWave. The gateway runs on a Raspberry Pi 3 and is connected through Ethernet to a home's wireless router. A custom component was written that automatically discovers and pulls data from the UMDS and AirU sensors. CoAP (Constraint Application Protocol) was used as the communication protocol between the sensors and gateway. CoAP is a UDP (User Datagram Protocol)-based protocol with similar semantics to HTTP. In our architecture, the AirU and UMDS sensors act as CoAP servers, and the gateway acts as a CoAP client. Periodically, the gateway will send a discovery message (a GET request to CoAP's specified multicast address) looking for new sensors. When a sensor receives this message, it responds back with information about itself, such as its type (AirU or UMDS) and ID. Once a sensor has been discovered, the gateway periodically pulls data from it. After the gateway receives data from a sensor, it tags the data with a unique ID for that gateway, and it uploads data to a central database. The gateway is the central hub of communication for our architecture. The gateway and sensors are co-located in the home, and the database (InfluxDB) is in the cloud.

\section{Data Analysis}

The data analysis focused on the following four components: calibration measurements, the distributed deployment, detection limits, and air exchange rates (AERs). The calibration measurements included evaluations of the time-series $\mathrm{PM}_{2.5}$ concentrations/counts and linear-regression modeling for each AirU and UMDS versus the mass-adjusted DustTrak $\mathrm{PM}_{2.5}$ concentrations (described below) for different types of aerosols. This enabled each sensor to be bias corrected. In addition, the GRIMM PM $\mathrm{P}_{2.5}$ concentrations were included in the time-series evaluations, and the average of all AirUs and the average of all UMDSs were fit with a linear model versus the mass-adjusted GRIMM PM ${ }_{2.5}$ mass concentrations. During the calibration period in Home I, one of the GRIMMs lost data for 1 day, and the other GRIMM registered an unknown peak not identified by the other two research-grade instruments or any of the fourteen low-cost sensors. Consequently, the majority of this evaluation focused on the low-cost sensors and the DustTrak $\mathrm{PM}_{2.5}$ measurements.

The raw mass concentrations from the GRIMM and DustTrak were multiplied by a mass-adjustment factor (MAF) to provide the mass-adjusted DustTrak or GRIMM 
measurements:

$$
M A F=\frac{M V_{-} \mathrm{PM}_{2.5, a v g}}{L S_{-} \mathrm{PM}_{2.5, \text { avg }}}
$$

where MAF $=$ mass adjustment factor (unitless), MV_PM 2.5 ,avg $=$ MiniVol mass concentration during the calibration period $\left(\mu \mathrm{g} \mathrm{m}^{-3}\right)$, and LS_PM $\mathrm{PM}_{2.5 \text {,avg }}=$ light-scattering instrument's (DustTrak or GRIMM) average concentration during the calibration period $\left(\mu \mathrm{g} \mathrm{m}^{-3}\right)$.

The MiniVol flow rate was confirmed using a Bios Defender 520 AirFlow Calibrator. The filters from the MiniVol were conditioned for 24 hours at $20^{\circ} \mathrm{C}$ and $20-30 \%$ relative humidity before and after sampling, and all samples were weighed in triplicate using a Mettler AE160 balance.

During the distributed study, each individual AirU and Dylos $\mathrm{PM}_{2.5}$ concentration/count was bias corrected, as described in the previous paragraph, and then an aerosolspecific CF was applied to obtain the best estimate of actual $\mathrm{PM}_{2.5}$ mass concentration. Only the DustTrak was used to develop the CFs, and CFs were generated for PM from candle burning, cooking, CAPs (outdoors with the UMDS) and general/unidentified PM events (Table S4). The CFs for candle burning and cooking were developed by collocating the DustTrak and MiniVol next to the PM generation source. The filter collection and weighing procedure are described in the previous paragraph. The candle burning was performed in a $0.3 \mathrm{~m}$ high, $0.3 \mathrm{~m}$ diameter cylindrical chamber and included burning/extinguishing six unscented tealight candles during a 4-hour period. For cooking, the DustTrak and MiniVol were collocated next to an outdoor gas grill, where vegetables and meat were grilled for 2 hours. The CF for the AirU and UMDS for candle burning and cooking were obtained by multiplying the AirU or UMDS by its corresponding MAF (bias correction) and then by the DustTrak/MiniVol (aerosol-specific CF). It was not possible to obtain filter measurements and CFs for Febreze ${ }^{\mathrm{TM}}$ and hairspray due to the volatile nature of Febreze $\mathrm{TM}^{\mathrm{TM}}$ and stickiness of the hairspray. Consequently, the CF for each individual AirU or UMDS obtained from the entire calibration week was used for the Febreze $^{\mathrm{TM}}$, hairspray and other unidentified activities. In addition, two of the UMDSs were collocated with the Utah Division of Air Quality's Thermo Scientific 1405-F Tapered Element Oscillating Microbalance (TEOM) during an 8-day period at the Hawthorne monitoring site to develop a factor for converting the UMDS small minus large particle count to $\mathrm{PM}_{2.5}$ mass concentration during CAPs (factor in Table S4). During this outdoor CAP calibration period, the $\mathrm{PM}_{2.5}$ levels ranged from 0 to $59.5 \mu \mathrm{g} \mathrm{m}^{-3}$ with a mean of $26.8 \mu \mathrm{g} \mathrm{m}^{-3}$.

Limited data is available regarding the limit of detection (LOD) for the PMS and Dylos sensors. Sayahi et al. (2019) reported that the PMS sensors had a LOD ranging from 2.62 to $11.5 \mu \mathrm{g} \mathrm{m}^{-3}$ (field evaluation), and Northcross et al. (2013) reported that the Dylos had a LOD of $1 \mu \mathrm{g} \mathrm{m}^{-3}$ (laboratory evaluation). An estimated LOD of $5 \mu \mathrm{g} \mathrm{m}^{-3}$ for the PMS sensor was selected from the reported range. The fraction of AirU measurements below $5 \mu \mathrm{g} \mathrm{m}^{-3}$ and UMDS measurements below $1 \mu \mathrm{g} \mathrm{m}^{-3}$ were considered in the discussion of the measurements. The effect of measurements below the estimated LODs on the fit coefficients from the linear regression were also considered. However, none of the data (whether below the reported LODs or not) were excluded from the evaluation.

The AERs were estimated for the different rooms in each home (Table S6) based on four PM spikes, using the method described by Burgess et al. (2004) and the time required for the $\mathrm{PM}_{2.5}$ concentration to decline by $90 \%$ from its peak value after the PM generation ceased:

$$
A E R=-\ln \left(\frac{C_{\max }}{C_{\min }}\right) \times \frac{1}{t}
$$

where $\mathrm{C}_{\max }$ and $\mathrm{C}_{\min }=$ maximum and minimum $\mathrm{PM}_{2.5}$ concentration $\left(\mu \mathrm{g} \mathrm{m}^{-3}\right)$ and $\mathrm{C}_{\max } / \mathrm{C}_{\min }=10, \mathrm{t}=$ time $(\mathrm{h})$ required to reduce the concentration from $\mathrm{C}_{\max }$ to $\mathrm{C}_{\min }$, and $\mathrm{AER}=$ number of air changes per hour $\left(\mathrm{h}^{-1}\right)$ and is a function of ventilation rate that has been normalized by the room volume.

The estimated AERs assume that the air is well mixed and that the concentration of $\mathrm{PM}_{2.5}$ in the incoming air is small compared to $\mathrm{C}_{\max }$ and $\mathrm{C}_{\min }$. It is important to note that the AER measurements during this study are representative of the AER at the time of the annotated activity and that at other times of the day, AER can vary significantly from the ones calculated.

\section{RESULTS AND DISCUSSION}

\section{Calibration of Sensors}

Fig. 1 shows how PM concentrations from the low-cost and research-grade sensors respond to a variety of household events during calibration week in Home I (Table S1) although some activities that increased PM levels were not annotated. $\mathrm{PM}_{2.5}$ concentrations increased rapidly when cooking and heating oil in the kitchen, which is close to the bedroom (Fig. S1), when spraying Febreze ${ }^{\mathrm{TM}}$ and using the humidifier in the bedroom (Table S1). Cooking activity in the kitchen (Table S1) caused smaller spikes in PM levels in the bedroom compared to candle burning activities, which occurred in the bedroom.

Fig. 2 compares the responses of the average of four AirUs and ten UMDSs with the DustTrak to a variety of household activities during the 6-day calibration period in Home I (Table S1). The different activities from the calibration period resulted in a scatter plot with distinct strips, and these strips corresponded to $\mathrm{PM}_{2.5}$ from different sources. Light-scattering-based measurements depend on aerosol optical properties (size, density and refractive index) (Jiang, 2010; TSI Inc., 2012), and for accurate mass concentration estimates from different aerosols, appropriate CFs are required (Jiang et al., 2011). Several researchers have found different CFs for different sources. For example, Jiang et al. (2011) found CFs for secondhand smoke (SHS), incense and toast that differed by more than a factor of 2 (TSI SidePak). Dacunto et al. (2013) estimated CFs for common indoor PM sources including cigarettes, candles, cooking and incense using a TSI SidePak. These also varied 


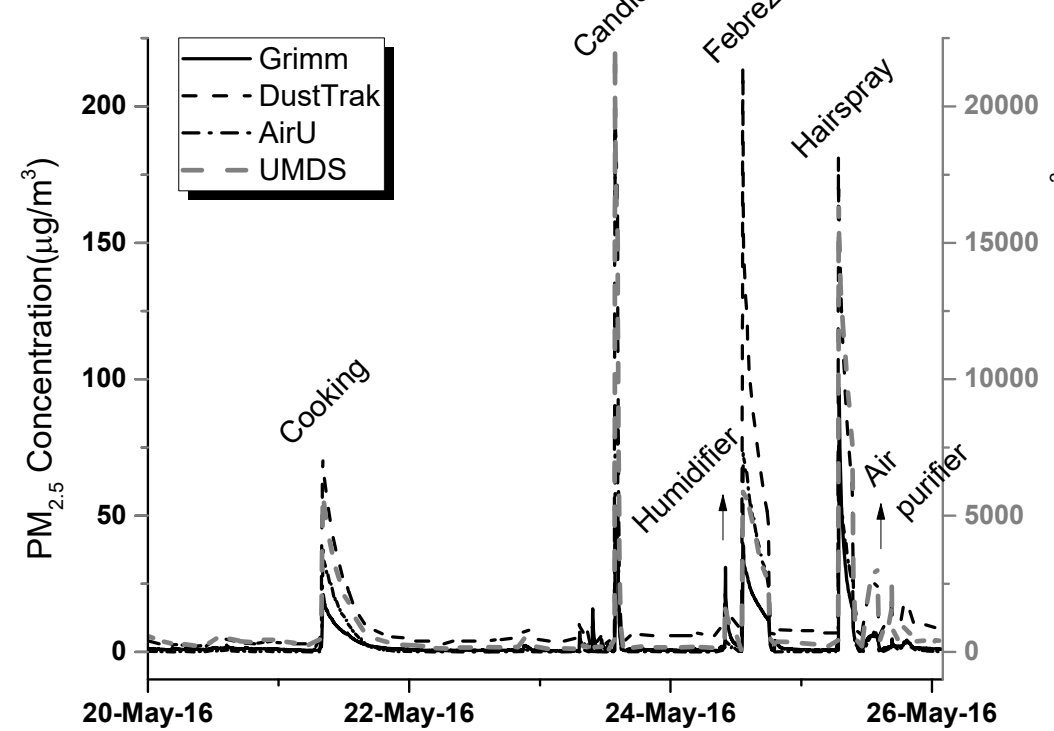

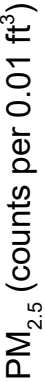

Fig. 1. Comparison of co-located 5-minute rolling average of $\mathrm{PM}_{2.5}$ concentrations $\left(\mu \mathrm{g} \mathrm{m}^{-3}\right)$ measured by a Grimm, DustTrak, average of 4 AirUs and average of 10 UMDSs $\left(\mathrm{PM}_{2.5}\right.$ count, small minus large bins, per $\left.0.01 \mathrm{ft}^{3}\right)$ for the calibration period of $20^{\text {th }}-25^{\text {th }}$ May 2016 (Home I). The concentrations measured by all sensors were uncorrected raw data.
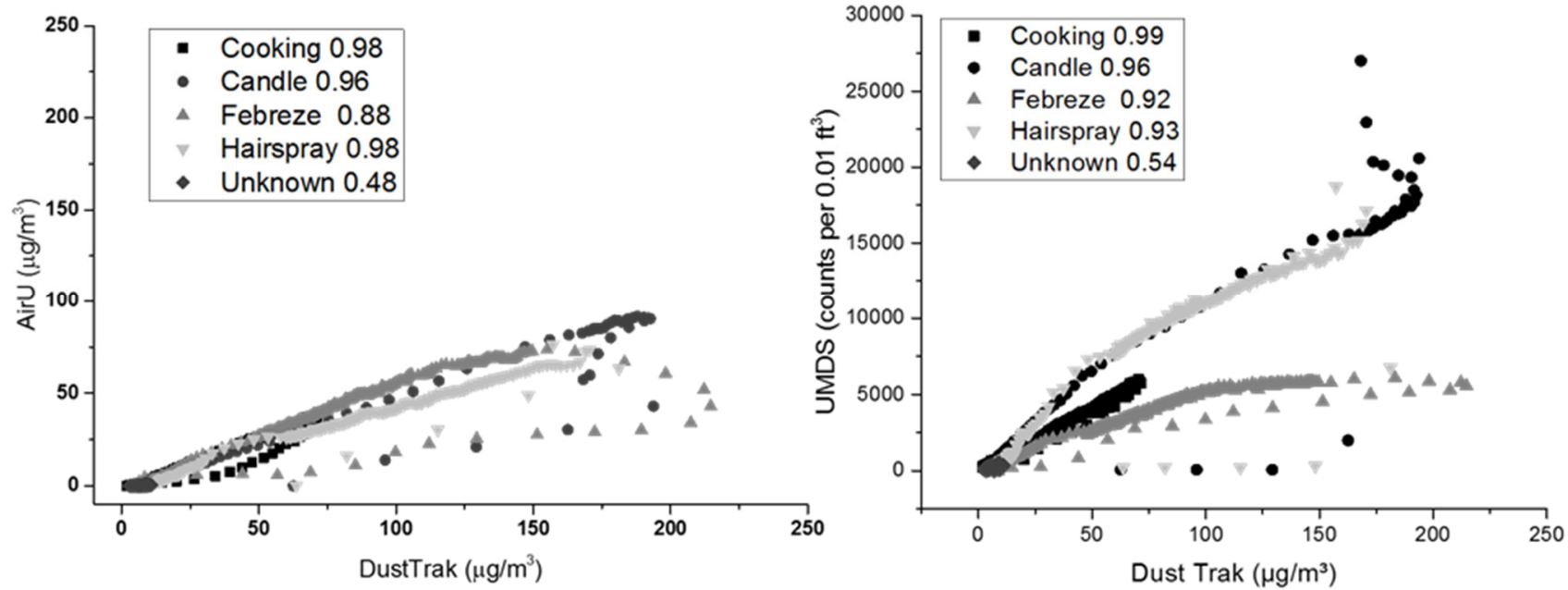

Fig. 2. Scatter plots and coefficients of determination $\left(\mathrm{R}^{2}\right)$ of the linear model (low-cost sensor and DustTrak) for 5-minute rolling average of $\mathrm{PM}_{2.5}$ concentrations $\left(\mu \mathrm{g} \mathrm{m}^{-3}\right)$ for several types of aerosols measured with a DustTrak (uncorrected), average of 4 AirUs (uncorrected) and average of $10 \mathrm{UMDSs}$, uncorrected $\left(\mathrm{PM}_{2.5}\right.$ count, small minus large bins, per $\left.0.01 \mathrm{ft}^{3}\right)$ during $20^{\text {th }}-25^{\text {th }}$ May 2016 (Home I).

by a factor of 2 depending on the source. The CFs in this study for cooking and candle burning differ by more than a factor of 2.5 (Table S4(c)). The slopes of the linear regression for different activities (aerosols) can be found in Table S2. Fig. S2 compares the response of the AirU and the UMDS with the GRIMM. Note that one GRIMM detected a PM event (not annotated) not detected by the two reference instruments or any of the fourteen low-cost sensors. Consequently, the comparisons with the GRIMM are presented only in the supplementary material.

Aerosol optical properties depend on their composition and size, and common indoor aerosols exhibit a variety of optical properties. For example, the main ingredient in Febreze ${ }^{\mathrm{TM}}$ is a water-alcohol mixture, with a refractive index (RI) of 1.33 (water)-1.36 (ethanol) (Andher et al., 2015). Hair-care products, like hairspray, contain mixtures of polymers in a glycol-water solvent, and glycol-water mixtures (10-80\% ethylene glycol) have a RI in the range of 1.39-1.42 (Sun et al., 2005). Cooking emissions from oils contain particles with RI of 1.46-1.47 (Lide, 2005). Candle burning results in fine carbon particles with a diverse range of RI (1.75-1.95) and adsorbed hydrocarbons (Poudel et al., 2017).

The four AirUs correlated well with each other $\left(\mathrm{R}^{2}=\right.$ $0.907-0.985)$, as did the ten UMDSs $\left(\mathrm{R}^{2}=0.952-0.997\right)$ (Figs. S3 and S4). However, for these intra-sensor comparisons, the slopes of the linear regressions were not always equal to 
1. For example, comparing the AirU sensors showed that slopes of the linear regressions for two of the sensors agreed within $5 \%$, for three sensors agreed within $10 \%$ and for all of the sensors agreed within $25 \%$. All of the slopes of the linear regressions for the UMDS sensors in Home I agreed within $40 \%$, while the slopes for five of the sensors agreed within $10 \%$. Intra-sensor variability has been previously reported for both the PMS and the Dylos sensors (Collingwood et al., 2019; Sayahi et al., 2019).

The correlations between the UMDS and the DustTrak are in the range reported in laboratory $\left(\mathrm{R}^{2}=0.81\right.$; Northcross et $a l ., 2013)$ and in ambient studies $\left(\mathrm{R}^{2}=0.78\right.$; Holstius et al., 2014). In addition, Semple et al. (2013) (Dylos vs. TSI SidePak AM510: $\mathrm{R}^{2}=0.86$ ) and Klepeis et al. (2013) (Dylos vs. DustTrak: $\left.\mathrm{R}^{2}>0.98\right)$ determined the relationship between $\mathrm{PM}_{2.5}$ mass concentration and Dylos response for SHS from tobacco. Although these studies did not investigate how the Dylos responded to other common indoor PM sources, they found that the Dylos sensors responded adequately to changes in PM levels caused by SHS. In a laboratory evaluation of the Dylos, the SCAQMD observed that the Dylos showed good correlation $\left(\mathrm{R}^{2}>0.89\right)$ with reference monitors, but it overestimated the $\mathrm{PM}_{2.5}$ concentrations as measured by the GRIMM (SCAQMD, 2017). Han et al. (2016) made a similar observation. Kelly et al. (2017) evaluated the Plantower PMS sensor (used in the AirU) during a winter period with several CAPs and found an $\mathrm{R}^{2}>0.88$ with Federal Reference Methods, but the PMS sensors overestimated $\mathrm{PM}_{2.5}$ concentrations when $\mathrm{PM}_{2.5}$ levels exceed $10 \mu \mathrm{g} \mathrm{m}^{-3}$ (Kelly et al., 2017). As Fig. 1 illustrates, both the AirU and the UMDS track indoor activities that caused significant changes in PM levels. The calibration results for Home II can be found in the supplemental data (Figs. S5-S8 and Table S3). The correlations between the UMDS and the GRIMM (Fig. S2) are in the same range as those reported in different settings: ambient (Williams et al., 2014: $\mathrm{R}^{2}=0.533$; Han et al., 2016: $\mathrm{R}^{2}=$ 0.778; Holstius et al., 2014: $\mathrm{R}^{2}=0.99$ ) and indoor (Taylor et al., 2016: $\left.\mathrm{R}^{2}=0.74\right)$.

\section{Effect of Household Activities on Indoor PM2.5 Levels}

During the distributed deployment, the sensors in different rooms (Fig. S1) responded to typical activities that occurred in the room where the sensor was located as well as activities that occurred in adjoining rooms. The home occupants periodically noted activities by manually recording the events. Tables 2 and 3 summarize the average and maximum concentration (obtained by applying the average CF from calibration week) during this part of the study for Home I and II, respectively. On average, the $\mathrm{PM}_{2.5}$ levels in Home I (summer) were well below the EPA and WHO 24-hour and annual standards. Home II $\mathrm{PM}_{2.5}$ levels were much closer to the EPA and WHO annual standards. The differences between homes may be due to seasonal differences in outdoor PM levels or differences in the homes and the associated HVAC systems. Specifically, Home I was built in 2002 and Home II in 1942. Apart from the high PM levels caused by fireworks ( $4^{\text {th }}$ of July), the winter CAP events caused higher average outdoor levels than those observed in summer.

The average $\mathrm{PM}_{2.5}$ concentrations in Home I (Table 2) are below the AirU's LOD of $5 \mu \mathrm{g} \mathrm{m}^{-3}$ (field evaluation; Sayahi et al., 2019) and are close to the UMDS's LOD of $1 \mu \mathrm{g} \mathrm{m}^{-3}$ (laboratory evaluation; Northcross et al., 2013). During the calibration week, less than $15 \%$ of the AirU measurements were below the LOD of $5 \mu \mathrm{g} \mathrm{m}^{-3}$, whereas, less than $6 \%$ of

Table 2. $\mathrm{PM}_{2.5}$ concentrations during the summer sampling period $\left(1^{\text {st }}-10^{\text {th }}\right.$ June 2016$)$ in Home I. $^{\text {a }}$

\begin{tabular}{llllll}
\hline Room & Sensors & Average $\left(\mu \mathrm{g} \mathrm{m}^{-3}\right)$ & Maximum $\left(\mu \mathrm{g} \mathrm{m}^{-3}\right)$ & S.D. $^{\mathrm{b}}\left(\mu \mathrm{g} \mathrm{m}^{-3}\right)$ & \% of data below LOD \\
\hline Outside & AirU 3 & 5.70 & 33.0 & 2.31 & 11.6 \\
& UMDS 110 & 3.10 & 54.4 & 12.8 & 13.8 \\
Living Room & AirU 8 & 1.82 & 18.0 & 1.98 & 57.6 \\
& UMDS 115 & 4.15 & 90.8 & 6.89 & 0 \\
Kitchen & AirU 2 & 2.57 & 89.0 & 4.54 & 53.1 \\
& UMDS 124 & 3.45 & 113 & 7.12 & 0 \\
Bedroom & AirU 6 & 5.62 & 642.0 & 27.84 & 58.9 \\
& UMDS 13 & 6.71 & 233.0 & 17.89 & 10.3 \\
\hline
\end{tabular}

${ }^{a} \mathrm{PM}_{2.5}$ concentrations corrected using an individual bias correction for each sensor based on the calibration week.

b S.D.: Standard deviation.

Table 3. $\mathrm{PM}_{2.5}$ concentrations during the winter sampling period ( $31^{\text {st }}$ January- $9^{\text {th }}$ February 2017) in Home II. ${ }^{\mathrm{a}}$

\begin{tabular}{llllll}
\hline Room & Sensors & Average $\left(\mu \mathrm{g} \mathrm{m}^{-3}\right)$ & Maximum $\left(\mu \mathrm{g} \mathrm{m}^{-3}\right)$ & S.D. $^{\mathrm{c}}\left(\mu \mathrm{g} \mathrm{m}^{-3}\right)$ & $\%$ of data below LOD \\
\hline Outside & UMDS 124 & 12.0 & 44.5 & 14.3 & 0 \\
Living Room $^{\mathrm{b}}$ & UMDS 116 & 22.0 & 345 & 32.8 & 0 \\
Front Door & UMDS 121 & 20.4 & 258 & 26.0 & 0 \\
Bathroom & UMDS 114 & 17.8 & 471 & 24.8 & 0 \\
Bedroom & UMDS 117 & 20.0 & 227 & 21.2 & 0 \\
\hline
\end{tabular}

${ }^{a} \mathrm{PM}_{2.5}$ concentrations corrected using an individual bias correction for each sensor based on the calibration week.

$\mathrm{b}$ The living room in Home II represents a combined kitchen/living area. The cooking events occurred in the kitchen which is very close to the living area.

${ }^{\mathrm{c}}$ S.D.: Standard deviation. 
the UMDS measurements were below the LOD of $1 \mu \mathrm{g} \mathrm{m}^{-3}$ in Home I. In Home II, less than $1 \%$ of the UMDS measurements were below the LOD. Removing measurements below the estimated LOD resulted in a $6 \%$ maximum change in slope of the AirU vs. DustTrak. Tables 2 and 3 show the percent of measurements below the reported LODs in each room in Home I and II, respectively. Although the AirUs and the UMDSs have similar laser wavelengths, differences in their internal configurations and flow patterns may also lead to differences in sensitivities related to particle size. Particles entering the PMS sensor (AirU) must make three $90^{\circ}$ turns before reaching the laser, and larger particles do not reach the photodetector as efficiently as smaller particles (Kelly et al., 2017). In the UMDS, particles make one long, sweeping turn before they can reach the laser/photodetector. Kelly et al. (2017) also found that the PMS sensors tend to overestimate PM mass concentration for small particles and underestimate it for large particles. Consequently, the average and maximum concentrations exhibit somewhat unexpected trends. For example, in Home I (Table 2), the UMDS maximum concentration outside is $40 \%$ more than AirU, while in the living room, the UMDS maximum concentration is $80 \%$ more than the AirU concentration.

The room-to-room comparison showed good correlations in Home II, with $\mathrm{R}^{2}>0.72$ between all the UMDSs, while the sensors in Home I showed poor to no correlation between UMDSs $\left(\mathrm{R}^{2}>0.02\right)$. The AirU sensors in Home I also showed low room-to-room correlations $\left(\mathrm{R}^{2}>0.01\right)$ except between the sensors in living room and bedroom $\left(\mathrm{R}^{2}\right.$ $=0.92)($ Table S5). The size of the home and the proximity of the sensors to cooking and heating/burning sources appear to be important factors in how well the sensors in different rooms correlate with each other.

Identification of PM sources (or source categories) would be needed to select an appropriate CF to convert each lowcost PM measurement to an improved estimate of PM mass concentration. Research is underway to address these challenges by annotation and automatic source categorization.
Tolmie et al. (2016) highlight the importance of annotation in networked sensing systems in order to contextualize the data and reduce incorrect data interpretation. Fang et al. (2016) developed an indoor air-quality sensing system that is able to automatically detect and identify up to three sources of indoor pollution events. Moore et al. (2018) developed a system that allows in situ annotation and real-time interactive visualization from air-quality data collected by a network of Dylos monitors. Furthermore, even if the source category is known, CFs can vary within that category. For example the $\mathrm{CF}$ for cooking would depend on variables such as type of food, method of cooking and temperature (Dacunto et al., 2013). However, focusing on relative differences may be valuable for individuals trying to minimize their PM exposure.

The highest indoor PM levels occurred in the kitchen and bedroom, where the bulk of the annotated events occurred (Fig. S1). In addition, Home II was smaller, making the rooms with sensors closer to the rooms with the highest PM concentrations. In general, cooking that involved frying caused some of the highest levels in the kitchen and also affected nearby rooms. Use of candles and aerosol products, like Febreze ${ }^{\mathrm{TM}}$, were the main causes of the high levels of $\mathrm{PM}$ in the bedrooms. The effect of these events on the $\mathrm{PM}_{2.5}$ levels in the rooms and their effects in adjacent rooms are illustrated in Fig. 3, Fig. 4 and the supplemental data (Fig. S9). It should also be noted that room AERs can also influence maximum $\mathrm{PM}_{2.5}$ concentrations and decay times for an emission source (Ni et al., 2018; Singer and Delp, 2018). The time required for an aerosol to be removed from a room depends on the AER, type of emission source (i.e., cooking, cleaning, candle burning etc.) and characteristics of the aerosol particles (i.e., density, size, shape). The AER ranges observed in both homes (Home I: 0.27-1.96; Home II: 0.51-2.66) (Table S6) are in the ranges reported by Rosofsky et al. (2019) (0.36-0.74) and Yamamoto et al. (2010) (0.37-1.13) for U.S. residences.

Bekö et al. (2013) report candle burning as a significant contributor to high indoor particulate levels. Our study supports

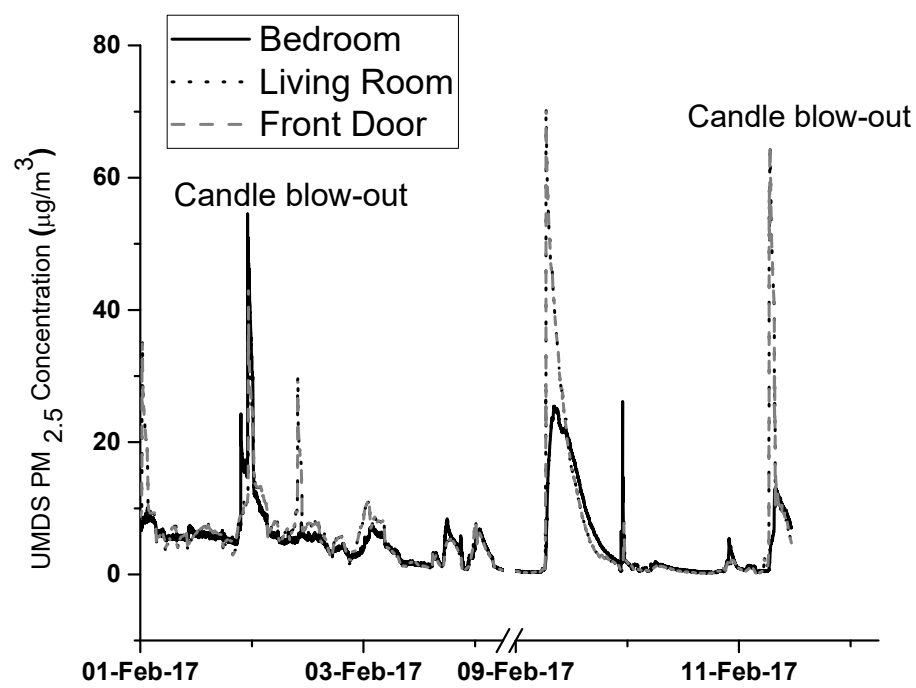

Fig. 3. Change in $\mathrm{PM}_{2.5}$ levels in other rooms when blowing out a candle (Home II). $\mathrm{PM}_{2.5}$ measurements from the UMDS (bedroom, living room, front door) were individually bias corrected with a CF for candle smoke (Table S4). 


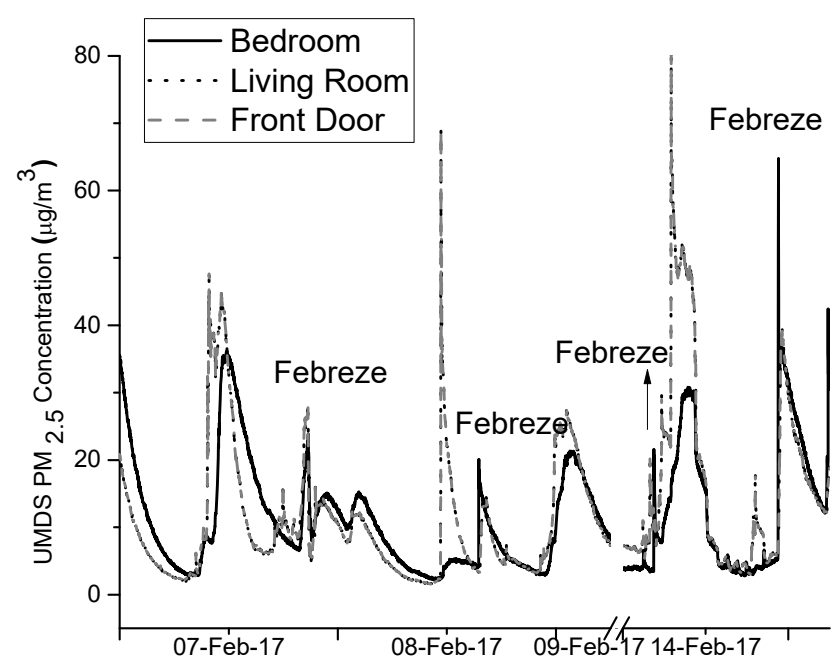

Fig. 4. Increase in $\mathrm{PM}_{2.5}$ levels in the room of activity and adjacent rooms when spraying Febreze ${ }^{\mathrm{TM}}$ (Home II). PM 2.5 measurements from the UMDS (bedroom, living room, front door) were individually bias corrected with a CF for the calibration week (Table S4).

this (Fig. 3). Initially, lighting the candle in the bedroom generated a spike, but the largest spike (5-fold increase in PM levels) came from extinguishing the candle, as reported by Afshari et al. (2005) and Hussein et al. (2006). Dacunto et al. (2013) also found that the vast majority of $\mathrm{PM}_{2.5}$ measured by a Dylos was emitted while candles were being extinguished. In this study, the increased $\mathrm{PM}_{2.5}$ levels from candle extinguishing lasted between 3 and 5 hours. Blowing out a candle also affected PM levels in adjacent rooms, causing a spike 3 to 4 times the background PM level in that room.

The use of aerosol products like Febreze ${ }^{\mathrm{TM}}$ air freshener (Fig. 4) and hairspray (Fig. S9) caused a sharp transient spike in PM levels with a long decay time, which was also observed during the calibration week. For example, spraying Febreze $^{\mathrm{TM}}$ (bedroom) showed an initial sharp spike, with $\mathrm{PM}_{2.5}$ levels above $75 \mu \mathrm{g} \mathrm{m}^{-3}$ for up to 20 minutes, and PM levels required up to 6 hours to decay to background levels. $\mathrm{PM}_{2.5}$ levels for hairspray showed a similar trend with $\mathrm{PM}_{2.5}$ levels increasing above $200 \mu \mathrm{g} \mathrm{m}^{-3}$ and decay time of up to 2 hours. Hairspray used in the bathroom did not appear to affect $\mathrm{PM}_{2.5}$ levels in other rooms, perhaps because the door was closed. Isaxon et al. (2015) also observed hairspray to cause an increase in $\mathrm{PM}_{1}$ levels, with levels close to $100 \mu \mathrm{g} \mathrm{m}^{-3}$.

In the kitchen, cooking (frying) activities increased $\mathrm{PM}_{2.5}$ levels up to $150 \mathrm{\mu g} \mathrm{m}^{-3}$ (Fig. 5). Both homes had 4-burner electric stoves. Home I had an over-the-range microwave fan filtered the cooking emissions, while Home II did not have any hood or venting system. Dacunto et al. (2013) and Jiang et al. (2011) found that cooking generally did not generate very high PM levels unless it involved frying or burning of food. Dacunto et al. (2013) reported that frying, particularly frying meat in oil tended to produce greater PM emissions than burning candles or incense. Loo et al. (2014) developed a wireless network that included a PMS Lasair II110 and a TSI AeroTrak optical particle counter that measured a 10-fold increase in PM levels from cooking. A particularly interesting event occurred in Home II when cooking steak, which showed that the indoor levels rose above outdoor PM levels, even during a winter CAP when $\mathrm{PM}_{2.5}$ levels were high. The sensor host did not annotate other cooking activities during the calibration or the distributed deployment.

PM levels during other common household activities like cleaning depended on the type of activity, the duration of the activity and its intensity. For example, making a bed generated a smaller spike, of a 2-fold increase, and vacuuming generated larger spikes, between 2- and 3-fold increases, where particles lingered for about 60 minutes (Fig. S10). Indoor PM levels in Home II on a winter day displayed a sawtooth pattern, which appeared to be caused by the furnace turning on and off (Fig. S11). The furnace caused PM level to vary from $20-42 \%$ over background levels. These regular increases may be caused by resuspension of particles in the heating ducts.

\section{Outdoor PM2.5 and its Effect on Indoor Levels}

Ambient sources of PM are an important contributor to indoor PM levels (Qing et al., 2005; Wheeler et al., 2011; Goyal and Kumar, 2013). In this study, we identified one case where elevated PM levels outdoor had a significant effect on indoor air and one where it did not. In Home II, the PM levels outside were consistently high (between 30 to $40 \mu \mathrm{g} \mathrm{m}^{-3}$; corrected UMDS) and opening a window ( $31^{\text {st }}$ Jan) for a mere 5 minutes raised PM levels inside the house in all three rooms for up to 50 minutes. Jin et al. (2015) also found that opening a window for an hour caused $\mathrm{PM}_{2.5}$ levels indoors to increase (by $9 \%$ when outdoor levels were $100 \mu \mathrm{g} \mathrm{m}^{-3}$ and by $20 \%$ when outdoor levels were $300 \mu \mathrm{g} \mathrm{m}^{-3}$ ). Rodes et al. (2001) found that indoor $\mathrm{PM}_{2.5}$ concentrations, on average, were only $45 \%$ of outdoor concentrations, but reached $80 \%$ when homes were ventilated through open windows (AprilMay). In addition, the baseline $\mathrm{PM}_{2.5}$ concentrations slowly increased over the course of the CAP (Fig. 6). During a week-long CAP period when outdoor $\mathrm{PM}_{2.5}$ levels were close to $35 \mu \mathrm{g} \mathrm{m}^{-3}$, PM levels indoors began to increase from a background level of $5 \mu \mathrm{g} \mathrm{m}^{-3}\left(25^{\text {th }} \mathrm{Jan}\right)$ to $10 \mu \mathrm{g} \mathrm{m}^{-3}$ 


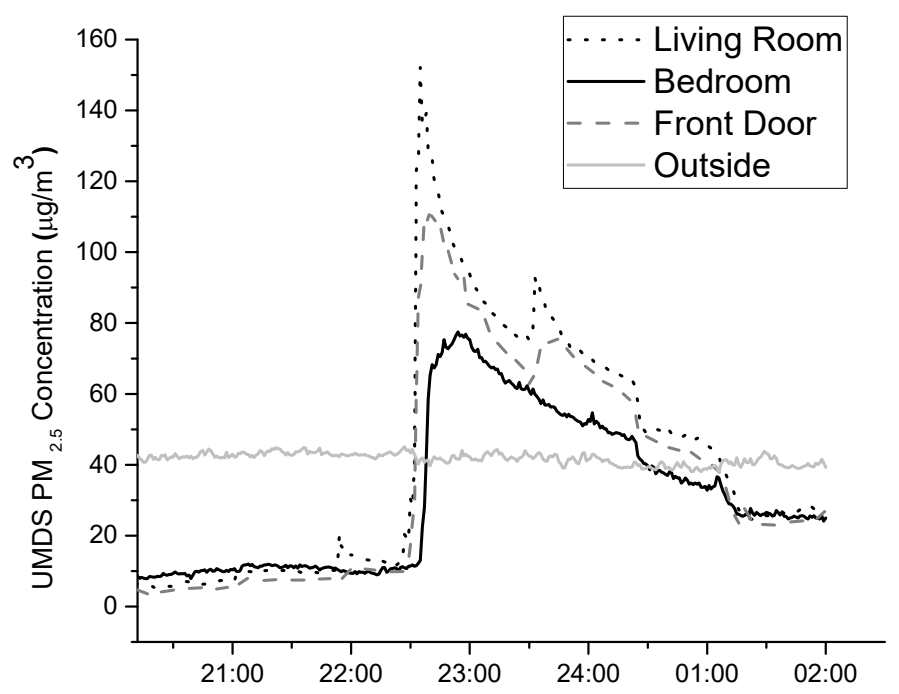

Fig. 5. High $\mathrm{PM}_{2.5}$ levels in Home II caused by cooking steak in the kitchen/living room ( $31^{\text {st }}$ January 2017$)$. $P M_{2.5}$ measurements from the UMDS (bedroom, living room, front door) were individually bias corrected with a CF for cooking (Table S4). $\mathrm{PM}_{2.5}$ measurements from the Outside UMDS was corrected with the CF for the CAP (Table S4).

(29 $9^{\text {th }}$ Jan) (Fig. 6). In two studies made in different climate zones by Kulmala and Vesala (1991) and Morawska et al. (2001), indoor concentrations followed the outdoor concentration changes in a smoothed and delayed pattern.

In contrast to the CAP event, on the $4^{\text {th }}$ of July holiday, the AirU sensor showed high outdoor PM levels beginning around 9 PM associated with the fireworks display (Fig. S12). These high outdoor levels caused by fireworks were consistent with previous studies that found large increases in PM levels associated with fireworks (Lin, 2016: 9-fold during fireworks in Western countries; Seidel and Birnbaum, 2015: 42\% increase in the U.S.). However, the elevated levels of $\mathrm{PM}_{2.5}$ were not seen inside the home, which had windows closed.

\section{Effect of Humidity on Light-scattering Measurements}

During this study, outdoor humidity levels outside Home I appear to follow a similar pattern to outdoor $\mathrm{PM}_{2.5}$ levels (Fig. S13). This diurnal humidity pattern is typical of $\mathrm{RH}$ during summer in Salt Lake City. Both the AirU and the UMDS use light scattering to estimate $\mathrm{PM}_{2.5}$ concentrations/particle count. A variety of factors affect particle light scattering, including particle size, shape, composition and relative humidity (RH) (Johnson et al., 2016). Since many aerosols are hygroscopic, changes in humidity can affect particle size and consequently particle mass estimated by light scattering. Both the UMDS and AirU contained sensors for measuring humidity. The UMDS had an SHT21 Sensirion humidity sensor, while the AirU had an Aosong Electronics DHT22 humidity sensor. Although the RH levels from the two different RH sensors are offset, the trends are consistent with each other and with high-quality RH measurements in the vicinity (MesoWest, 2018; Weather Underground, 2018). During the time period illustrated in Fig. S13, RH varied from less than 10 to $75 \%$, and both the lower $\mathrm{RH}$ and the upper RH levels can affect light-scattering PM measurements. Chakrabarti et al. (2004) and Soneja et al. (2014) found that at RH of less than 20 or $30 \%$, respectively. Several studies have reported that light-scattering instruments substantially and nonlinearly overestimated mass concentrations at RH levels higher than 70\% (Sioutas et al., 2000; Chakrabarti et al., 2004; Wu et al., 2005). Other researchers found that when RH increased above 50\% (Day and Malm, 2001) to 75\% (Chakrabarti et al., 2004; Soneja et al., 2014) a humidity correction was needed for nephelometers. Our results suggest that the effect of RH on these low-cost PM sensor measurements requires further evaluation.

\section{CONCLUSIONS}

This study demonstrated that two low-cost PM sensors, the AirU and the UMDS, accurately tracked indoor and outdoor variations in PM concentrations (compared to research-grade instruments) and also exhibited good intrasensor agreement, indicating that they provide reliable relative measurements of the concentration, e.g., if the measured concentration doubles, it reflects an actual doubling of the real concentration. Sharp increases in the $\mathrm{PM}_{2.5}$ levels were produced by several indoor activities, including frying food, burning candles, and spraying aerosol products, in the rooms where they occurred as well as in adjacent rooms. In both homes, the highest $\mathrm{PM}_{2.5}$ concentrations were measured in the kitchen and the bedroom. Elevated outdoor $\mathrm{PM}_{2.5}$ levels during a CAP event also caused indoor levels to rise over both the short and the long term. Finally, the sensors responded differently to different PM sources due to the latter's varying optical properties. Consequently, obtaining accurate estimates of the mass concentration in an indoor environment is challenging because it requires a specific $\mathrm{CF}$ for each sensor and source type, which in turn requires a strategy to identify each source. However, low-cost PM sensors can be incorporated into an indoor air-quality measurement network to help individuals manage their personal exposure. 


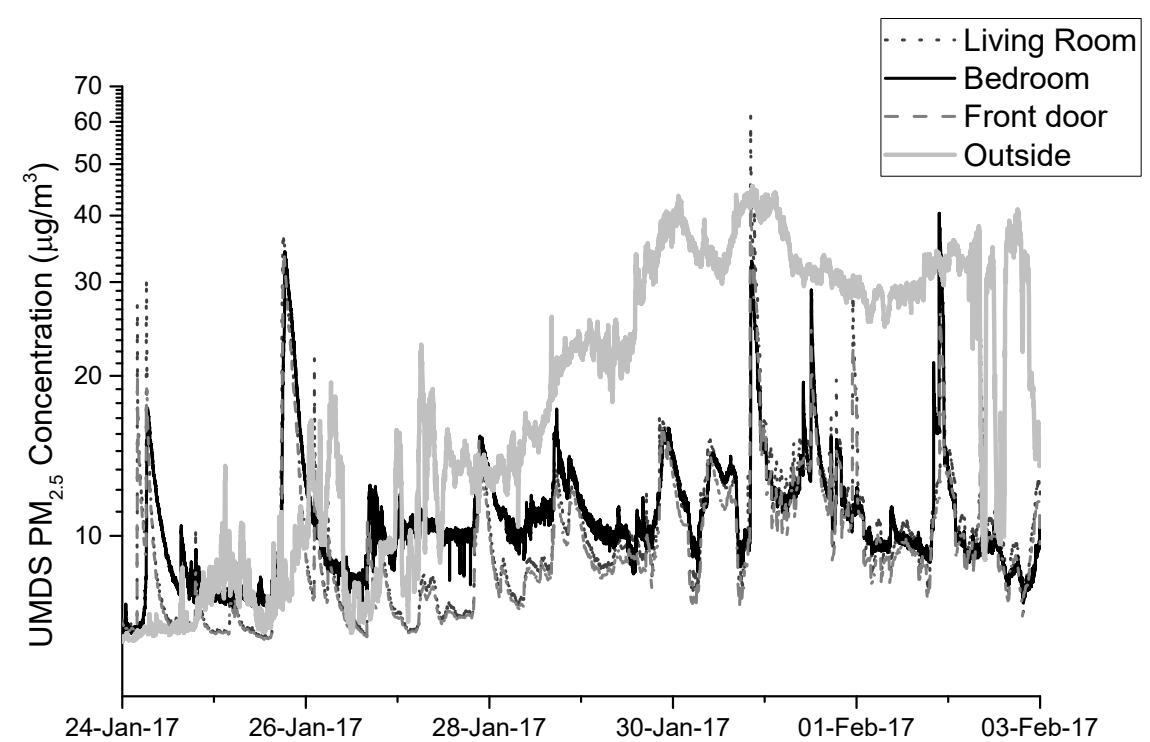

Fig. 6. $\mathrm{PM}_{2.5}$ levels during a winter CAP from $24^{\text {th }}$ January to $3^{\text {rd }}$ February 2017 (Home II). PM 2.5 measurements from the UMDS (bedroom, living room, front door) were individually bias corrected with a $\mathrm{CF}$ for the calibration week. $\mathrm{PM}_{2.5}$ measurements from the outside UMDS was corrected with the CF for the CAP (Table S4).

\section{ACKNOWLEDGEMENTS}

We gratefully acknowledge support by NIH Grant Number U54EB021973, Prisms Informatics PlatformFederated Integration Architecture and the ECHO Program, National Institutes of Health under Award Number UH3OD023249.

\section{CONFLICT OF INTEREST}

Dr. Kerry Kelly, co-author on this paper, has a financial interest in the company Tetrad: Sensor Network Solutions, LCC, which commercializes solutions for environmental monitoring.

\section{SUPPLEMENTARY MATERIAL}

Supplementary data associated with this article can be found in the online version at http://www.aaqr.org.

\section{REFERENCES}

Afshari, A., Matson, U. and Ekberg, L.E. (2005). Characterization of indoor sources of fine and ultrafine particles: A study conducted in a full-scale chamber. Indoor Air 15: 141-150. doi: 10.1111/j.1600-0668.2005. 00332.x.

Alvarado, M., Gonzalez, F., Fletcher, A. and Doshi, A. (2015). Towards the development of a low cost airborne sensing system to monitor dust particles after blasting at open-pit mine sites. Sensors 15: 19667-19687. doi: 10.3390/s150819667.

Amaral, S.S., De Carvalho, A.J., Costa, A.M. and Pinheiro, C. (2015). An overview of particulate matter measurement instruments. Atmosphere 6: 1327-1345. doi: 10.3390/atm os6091327.
Anderson, J.O., Thundiyil, J.G. and Stolbach, A. (2012). Clearing the air: A review of the effects of particulate matter air pollution on human health. J. Med. Toxicol. 8: 166-175. doi: 10.1007/s13181-011-0203-1.

Andher, S., Gadhawala, Z., Vyas, S., Goswami, K., Desai, A., Desai, C., Desai, D., Desai, G. and Desai, P. (2015). Comparative study of Specific Refraction of Potassium salts solutions in Binary (Ethanol+Water) mixtures. Res. J. Phys. Sci. 3: 1-4.

Austin, E., Novosselov, I., Seto, E. and Yost, M.G. (2015). Laboratory evaluation of the Shinyei PPD42NS low-cost particulate matter sensor. PLoS One 10: 1-17. doi: 10.1371/journal.pone.0137789.

Bekö, G., Weschler, C.J., Wierzbicka, A., Karottki, D.G., Toftum, J., Loft, S. and Clausen, G. (2013). Ultrafine particles: Exposure and source apportionment in 56 Danish homes. Environ. Sci. Technol. 47: 10240-10248. doi: 10.1021/es402429h.

Bo, M., Salizzoni, P., Clerico, M. and Buccolieri, R. (2017). Assessment of indoor-outdoor particulate matter air pollution: A review. Atmosphere 8: 136. doi: 10.3390/atm os8080136.

Braniš, M., Řezáčová, P. and Domasová, M. (2005). The effect of outdoor air and indoor human activity on mass concentrations of $\mathrm{PM}_{10}, \mathrm{PM}_{2.5}$, and $\mathrm{PM}_{1}$ in a classroom. Environ. Res. 99: 143-149. doi: 10.1016/j.envres.2004.12. 001.

Braniš, M., Šafránek, J. and Hytychová, A. (2009). Exposure of children to airborne particulate matter of different size fractions during indoor physical education at school. Build. Environ. 44: 1246-1252. doi: 10.1016/j.b uildenv.2008.09.010.

Brook, R.D., Rajagopalan, S., Pope, C.A., Brook, J.R., Bhatnagar, A., Diez-Roux, A.V., Holguin, F., Hong, Y., Luepker, R.V., Mittleman, M.A., Peters, A., Siscovick, D., Smith, S.C., Whitsel, L. and Kaufman, J.D. (2010). 
Particulate matter air pollution and cardiovascular disease: An update to the scientific statement from the american heart association. Circulation 121: 2331-2378. doi: 10.1161/CIR.0b013e3181dbece1.

Burgess, W.A., Ellenbecker, M.J. and Treitman, R.D. (2004). Ventilation for the control of the work environment, 2nd ed. John Wiley \& Sons, Inc., USA.

Castell, N., Dauge, F.R., Schneider, P., Vogt, M., Lerner, U., Fishbain, B., Broday, D. and Bartonova, A. (2017). Can commercial low-cost sensor platforms contribute to air quality monitoring and exposure estimates? Environ. Int. 99: 293-302. doi: 10.1016/j.envint.2016.12.007.

Chakrabarti, B., Fine, P.M., Delfino, R. and Sioutas, C. (2004). Performance evaluation of the active-flow personal DataRAM $\mathrm{PM}_{2.5}$ mass monitor (Thermo Anderson pDR-1200) designed for continuous personal exposure measurements. Atmos. Environ. 38: 3329-3340. doi: 10.1016/j.atmosenv.2004.03.007.

Collingwood, S., Zmoos, J., Pahler, L., Wong, B., Sleeth, D. and Handy, R. (2019). Investigating measurement variation of modified low-cost particle sensors. J. Aerosol Sci. 135: 21-32. doi: 10.1016/j.jaerosci.2019.04.017.

Dacunto, P.J., Cheng, K.C., Acevedo-Bolton, V., Jiang, R.T., Klepeis, N.E., Repace, J.L., Ott, W.R. and Hildemann, L.M. (2013). Real-time particle monitor calibration factors and $\mathrm{PM}_{2.5}$ emission factors for multiple indoor sources. Environ. Sci. Processes Impacts 15: 1511. doi: 10.1039/c3em00209h.

Dacunto, P.J., Klepeis, N.E., Cheng, K.C., Acevedo-Bolton, V., Jiang, R.T., Repace, J.L., Ott, W.R. and Hildemann, L.M. (2015). Determining $\mathrm{PM}_{2.5}$ calibration curves for a low-cost particle monitor: Common indoor residential aerosols. Environ. Sci. Processes Impacts 17: 1959-1966. doi: 10.1039/C5EM00365B.

Day, D.E. and Malm, W.C. (2001). Aerosol light scattering measurements as a function of relative humidity: A comparison between measurements made at three different sites. Atmos. Environ. 35: 5169-5176. doi: 10.1016/S1352-2310(01)00320-X.

Fang, B., Xu, Q., Park, T. and Zhang, M. (2016). AirSense: An intelligent home-based sensing system for indoor air quality analytics. UbiComp 2016 - Proceedings of the 2016 ACM International Joint Conference on Pervasive and Ubiquitous Computing. pp. 109-119. doi: 10.1145/29 71648.2971720.

Fromme, H., Twardella, D., Dietrich, S., Heitmann, D., Schierl, R., Liebl, B. and Rüden, H. (2007). Particulate matter in the indoor air of classrooms-exploratory results from Munich and surrounding area. Atmos. Environ. 41: 854-866. doi: 10.1016/j.atmosenv.2006.08.053.

Fromme, H., Diemer, J., Dietrich, S., Cyrys, J., Heinrich, J., Lang, W., Kiranoglu, M. and Twardella, D. (2008). Chemical and morphological properties of particulate matter $\left(\mathrm{PM}_{10}, \mathrm{PM}_{2.5}\right)$ in school classrooms and outdoor air. Atmos. Environ. 42: 6597-6605. doi: 10.1016/j.atmos env.2008.04.047.

Gao, M., Cao, J. and Seto, E. (2015). A distributed network of low-cost continuous reading sensors to measure spatiotemporal variations of $\mathrm{PM}_{2.5}$ in Xi'an, China.
Environ. Pollut. 199: 56-65. doi: 10.1016/j.envpol.2015. 01.013 .

Goyal, R. and Kumar, P. (2013). Indoor-outdoor concentrations of particulate matter in nine microenvironments of a mixuse commercial building in megacity Delhi. Air Qual. Atmos. Health 6: 747-757. doi: 10.1007/s11869-0130212-0.

GRIMM (2010). Specification for portable laser aerosol spectrometer and dust monitor Model 1.108/1.109. Users Man. 11.

Han, I., Symanski, E. and Stock, T.H. (2016). Feasibility of using low-cost portable particle monitors for measurement of fine and coarse particulate matter in urban ambient air. J. Air Waste Manage. Assoc. 67: 330-340. doi: 10.1080/10962247.2016.1241195.

Hering, S.V., Lunden, M.M., Thatcher, T.L., Kirchstetter, T.W. and Brown, N.J. (2007). Using regional data and building leakage to assess indoor concentrations of particles of outdoor origin. Aerosol Sci. Technol. 41: 639654. doi: 10.1080/02786820701368026.

Holstius, D.M., Pillarisetti, A., Smith, K.R. and Seto, E. (2014). Field calibrations of a low-cost aerosol sensor at a regulatory monitoring site in California. Atmos. Meas. Tech. 7: 1121-1131. doi: 10.5194/amt-7-1121-2014.

Hussein, T., Glytsos, T., Ondráček, J., Dohányosová, P., Ždímal, V., Hämeri, K., Lazaridis, M., Smolík, J. and Kulmala, M. (2006). Particle size characterization and emission rates during indoor activities in a house. Atmos. Environ. 40: 4285-4307. doi: 10.1016/j.atmosenv.2006.0 3.053 .

Isaxon, C., Gudmundsson, A., Nordin, E.Z., Lönnblad, L., Dahl, A., Wieslander, G., Bohgard, M. and Wierzbicka, A. (2015). Contribution of indoor-generated particles to residential exposure. Atmos. Environ. 106: 458-466. doi: 10.1016/j.atmosenv.2014.07.053.

Jeon, Y., Cho, C., Seo, J., Kwon, K., Park, H., Oh, S. and Chung, I. (2018). IoT-based occupancy detection system in indoor residential environments. Build. Environ. 132: 181-204.

Jiang, R. (2010). Airborne fine particulate matter pollution in casinos: Performance of a real-time particle monitor and personal exposure to secondhand smoke. $\mathrm{PhD}$ Thesis. Stanford University, USA.

Jiang, R.T., Acevedo-Bolton, V., Cheng, K.C., Klepeis, N.E., Ott, W.R. and Hildemann, L.M. (2011). Determination of response of real-time SidePak AM510 monitor to secondhand smoke, other common indoor aerosols, and outdoor aerosol. J. Environ. Monit. 13: 1695-1702. doi: 10.1039/c0em00732c.

Jin, W., Zhang, N. and He, J. (2015). Experimental study on the influence of a ventilated window for indoor air quality and indoor thermal environment. Procedia Engineering. pp. 217-224. doi: 10.1016/j.proeng.2015.08.1058.

Johnson, K.K., Bergin, M.H., Russell, A.G. and Hagler, G.S.W. (2016). Using low cost sensors to measure ambient particulate matter concentrations and on-road emissions factors. Atmos. Meas. Tech. Discuss., doi: 10.5194/amt-2015-331.

Jovašević-Stojanović, M., Bartonova, A., Topalović, D., 
Lazović, I., Pokrić, B. and Ristovski, Z. (2015). On the use of small and cheaper sensors and devices for indicative citizen-based monitoring of respirable particulate matter. Environ. Pollut. 206: 696-704. doi: 10.1016/j.envpol.20 15.08.035.

Kelly, K.E., Whitaker, J., Widmer, C., Dybwad, A. and Butterfield, A. (2017). Ambient and laboratory evaluation of a low-cost particulate matter sensor. Environ. Pollut. 221: 491-500. doi: 10.1016/j.envpol.2016.12.039.

Klepeis, N.E., Hughes, S.C., Edwards, R.D., Allen, T., Johnson, M., Chowdhury, Z., Smith, K.R., Boman-Davis, M., Bellettiere, J. and Hovell, M.F. (2013). Promoting smoke-free homes: A novel behavioral intervention using real-time audio-visual feedback on airborne particle levels. PLoS One 8: e73251. doi: 10.1371/journal.pone.00 73251.

Klepeis, N.E., Nelson, W.C., Ott, W.R., Robinson, J.P., Tsang, A.M., Switzer, P., Behar, J.V, Hern, S.C. and Engelmann, W.H. (2001). The National Human Activity Pattern Survey (NHAPS): A resource for assessing exposure to environmental pollutants. J. Exposure Anal. Environ. Epidemiol. 11: 231-252.

Kulmala, M. and Vesala, T. (1991). Condensation in the continuum regime. J. Aerosol Sci. 22: 337-346.

Kumar, P. and Morawska, L. (2013). Energy-pollution nexus for urban buildings. Environ. Sci. Technol. 47: 7591-7592. doi: 10.1021/es402549p.

Kumar, P., Skouloudis, A.N., Bell, M., Viana, M., Carotta, M.C., Biskos, G. and Morawska, L. (2016). Real-time sensors for indoor air monitoring and challenges ahead in deploying them to urban buildings. Sci. Total Environ. 560-561: 150-159. doi: 10.1016/j.scitotenv.2016.04.032.

Li, J., Li, H., Ma, Y., Wang, Y., Abokifa, A.A. and Lu, C. (2017). Spatiotemporal distribution of indoor particulate matter concentration with a low-cost sensor network. Build. Environ. 127: 138-147. doi: 10.1016/j.buildenv.20 17.11.001.

Lide, D.R. (2005). Hardness of minerals and ceramics, Internet V. (ed.), CRC Handbook of Chemistry and Physics. CRC Press, FL. doi: 10.1021/ja041017a.

Lin, C.C. (2016). A review of the impact of fireworks on particulate matter in ambient air. J. Air Waste Manage. Assoc. 66: 1171-1182. doi: 10.1080/10962247.2016.121 9280.

Loo, S.M., Hall, J.A., Kiepert, J., Pook, M. and Terrell, N. (2014). A low-cost wireless portable particulate matter monitoring system. 13th International Conference on Indoor Air Quality and Climate, Indoor Air, pp. 903-910.

Manikonda, A., Zíková, N., Hopke, P.K. and Ferro, A.R. (2016). Laboratory assessment of low-cost PM monitors. J. Aerosol Sci. 102: 29-40. doi: 10.1016/j.jaerosci.2016.08. 010 .

Moore, J., Pascal, G., Miriah, M., Philip, L., Patwari, N., Sward, K. and Wiese, J. (2018). Managing in-home environments through sensing, annotating, and visualizing air quality data. Proc. ACM Interact. Mob. Wearable Ubiquitous Technol. p. 28.

Morawska, L., He, C., Hitchins, J., Gilbert, D. and Parappukkaran, S. (2001). The relationship between indoor and outdoor airborne particles in the residential environment. Atmos. Environ. 35: 3463-3473. doi: 10.1016/S1352-2310(01)00097-8.

Northcross, A.L., Edwards, R.J., Johnson, M.A., Wang, Z.M., Zhu, K., Allen, T. and Smith, K.R. (2013). A lowcost particle counter as a realtime fine-particle mass monitor. Environ. Sci. Processes Impacts 15: 433. doi: 10.1039/c2em30568b.

Patel, S., Li, J., Pandey, A., Pervez, S., Chakrabarty, R.K. and Biswas, P. (2017). Spatio-temporal measurement of indoor particulate matter concentrations using a wireless network of low-cost sensors in households using solid fuels. Environ. Res. 152: 59-65. doi: 10.1016/j.envres.20 16.10.001.

Peters, T.M., Ott, D. and O'shaughnessy, P.T. (2006). Comparison of the Grimm 1.108 and 1.109 portable aerosol spectrometer to the TSI 3321 aerodynamic particle sizer for dry particles. Ann. Occup. Hyg. 50: 843-850. doi: 10.1093/annhyg/mel067.

Poudel, S., Fiddler, M., Smith, D., Flurchick, K. and Bililign, S. (2017). Optical properties of biomass burning aerosols: Comparison of experimental measurements and T-Matrix calculations. Atmosphere 8: 228. doi: 10.3390/at mos8110228.

Qing, Y.M., Turpin, B.J., Korn, L., Weisel, C.P., Morandi, M., Colome, S., Junfeng, Z., Stock, T., Spektor, D., Winer, A., Zhang, L., Jong, H.L., Giovanetti, R., Cui, W., Kwon, J., Alimokhtari, S., Shendell, D., Jones, J., Farrar, C. and Maberti, S. (2005). Influence of ambient (outdoor) sources on residential indoor and personal $\mathrm{PM}_{2.5}$ concentrations: Analyses of RIOPA data. J. Exposure Anal. Environ. Epidemiol. 15: 17-28. doi: 10.1038/sj.jea.7500378.

Rodes, C.E., Lawless, P.A., Evans, G.F., Sheldon, L.S., Williams, R.W., Vette, A.F., Creason, J.P. and Walsh, D. (2001). The relationships between personal PM exposures for elderly populations and indoor and outdoor concentrations for three retirement center scenarios. $J$. Exposure Anal. Environ. Epidemiol. 11: 103-115. doi: 10.1038/sj.jea.7500155.

Rosofsky, A., Levy, J.I., Breen, M.S., Zanobetti, A. and Fabian, M.P. (2019). The impact of air exchange rate on ambient air pollution exposure and inequalities across all residential parcels in Massachusetts. J. Exposure Sci. Environ. Epidemiol. 29: 520-530. doi: 10.1038/s41370018-0068-3.

Sayahi, T., Butterfield, A. and Kelly, K.E. (2019). Longterm field evaluation of the Plantower PMS low-cost particulate matter sensors. Environ. Pollut. 245: 932-940. doi: 10.1016/j.envpol.2018.11.065.

Seidel, D.J. and Birnbaum, A.N. (2015). Effects of Independence Day fi reworks on atmospheric concentrations of fi ne particulate matter in the United States. Atmos. Environ. 115: 192-198. doi: 10.1016/j.atmosenv.2015.05. 065.

Semple, S., Engku Ibrahim, A., Apsley, A., Steiner, M. and Turner, S. (2013). Using a new, low-cost air quality sensor to quantify second-hand smoke (SHS) levels in homes. Tob. Control. 24: 153-158. doi: 10.1136/tobaccoco ntrol-2013-051188. 
Singer, B.C. and Delp, W.W. (2018). Response of consumer and research grade indoor air quality monitors to residential sources of fine particles. Indoor Air 28: 624 639. doi: 10.1111/ina.12463.

Sioutas, C., Kim, S., Chang, M., Terrell, L.L. and Gong, H. (2000). Field evaluation of a modified DataRAM MIE scattering monitor for real-time $\mathrm{PM}_{2.5}$ mass concentration measurements. Atmos. Environ. 34: 4829-4838.

Soneja, S., Chen, C., Tielsch, J.M., Katz, J., Zeger, S.L., Checkley, W., Curriero, F.C. and Breysse, P.N. (2014). Humidity and gravimetric equivalency adjustments for nephelometer-based particulate matter measurements of emissions from solid biomass fuel use in cookstoves. Int. J. Environ. Res. Public Health 11: 6400-6416. doi: 10.3390/ijerph110606400.

Sorensen, M., Daneshvar, B., Hansen, M., Dragsted, L.O., Hertel, O., Knudsen, L. and Loft, S. (2003). Personal $\mathrm{PM}_{2.5}$ exposure and markers of oxidative stress in blood. Environ. Health Perspect. 111: 161-166. doi: 10.1289/ehp. 5646.

Spengler, J.D. and Sexton, K.A. (1983). Indoor air pollution: A public health perspective. Science 221: 9-17. doi: 10.1126/science.6857273.

Sun, J.Z., Erickson, M.C.E., Parr, J.W. and Schwarzkopf, H. (2005). Refractive index matching and clear emulsions. $J$. Cosmet. Sci. 56: 253-265.

Taylor, M.D., Nourbakhsh, I.R., Steinfeld, A., Presto, A. and Longhurst, J. (2016). Calibration and characterization of low-cost fine particulate monitors and their effect on individual empowerment. PhD Thesis, Carnegie Mellon University, USA.

Tolmie, P., Crabtree, A., Rodden, T., Colley, J.A. and Luger, E.A. (2016). "This has to be the cats" - Personal Data Legibility in Networked Sensing Systems. Proceedings of the 19th ACM Conference on Computer-Supported Cooperative Work \& Social Computing - CSCW '16. ACM, San Francisco, pp. 490-501. doi: 10.1145/2818048. 2819992.

TSI Inc. (2012). Sidepak ${ }^{\mathrm{TM}}$ AM510 Personal Aerosol Monitor Theory of Operation.

U.S. Department of Commerce (2010). US 2010 Census., 2010. Guide to State and Local Census Geography. U.S. Department of Commerce, USA.

U.S. Environmental Protection Agency (2014). Particulate Matter Concentrations. EPA's Report on the Environment (ROE), U.S. Environmental Protection Agency, USA.

Vercellino, R.J., Sleeth, D.K., Handy, R.G., Min, K.T., Collingwood, S.C., Vercellino, R.J., Sleeth, D.K., Handy, R.G. and Kyeong, T. (2018). Laboratory evaluation of a low-cost, real-time, aerosol multi-sensor. J. Occup. Environ. Hyg. 15: 559-567. doi: 10.1080/15459624.201 8.1468565 .

Wang, Y., Li, J., Jing, H., Zhang, Q., Jiang, J. and Biswas, P. (2015). Laboratory evaluation and calibration of three low-cost particle sensors for particulate matter measurement laboratory evaluation and calibration of three low-cost particle sensors for particulate matter measurement. Aerosol Sci. Technol. 49: 1063-1077. doi: 10.1080/02786826.2015.1100710.

Weekly, K., Rim, D., Zhang, L., Bayen, A.M., Nazaroff, W.W. and Spanos, C.J. (2013). Low-cost coarse airborne particulate matter sensing for indoor occupancy detection. 2013 IEEE International Conference on Automation Science and Engineering (CASE). pp. 32-37.

Wheeler, A.J., Wallace, L.A., Kearney, J., Ryswyk, K. Van, You, H., Kulka, R., Brook, J.R. and Xu, X. (2011). Personal, indoor, and outdoor concentrations of fine and ultrafine particles using continuous monitors in multiple residences. Aerosol Sci. Technol. 45: 1078-1089. doi: 10.1080/02786826.2011.580798.

Williams, R., Kaufman, A., Hanley, T., Rice, J. and Garvey, S. (2014). Evaluation of field-deployed low cost PM sensors. U.S. Environmental Protection Agency, Washington, DC, 2014, EPA/600/R-14/464 (NTIS PB 2015-102104).

World Health Organization (2006). WHO Air quality guidelines for particulate matter, ozone, nitrogen dioxide and sulfur dioxide: Global update 2005: Summary of risk assessment, World Health Organization, Geneva, doi: 10.1016/0004-6981(88)90109-6.

World Health Organization (2014). Burden of disease from household air pollution for 2012. World Health Organization, Geneva.

Wu, C.F., Delfino, R.J., Floro, J.N., Samimi, B.S., Quintana, P.J.E., Kleinman, M.T. and Sally Liu, L.J. (2005). Evaluation and quality control of personal nephelometers in indoor, outdoor and personal environments. J. Exposure Anal. Environ. Epidemiol. 15: 99-110. doi: 10.1038/sj.je a.7500351.

Yamamoto, N., Shendell, D.G., Winer, A.M. and Zhang, J. (2010). Residential air exchange rates in three major US metropolitan areas: Results from the Relationship Among Indoor, Outdoor, and Personal Air Study 1999-2001. Indoor Air 20: 85-90. doi: 10.1111/j.1600-0668.2009.00 622.x.

Zhang, J. and Smith, K.R. (2003). Indoor air pollution: A global health concern. Br. Med. Bull. 68: 209-225. doi: $10.1093 / \mathrm{bmb} / \mathrm{ldg} 029$.

Zhu, Y., Yang, L., Meng, C., Yuan, Q., Yan, C., Dong, C., Sui, X., Yao, L., Yang, F., Lu, Y. and Wang, W. (2015). Indoor/outdoor relationships and diurnal/nocturnal variations in water-soluble ion and $\mathrm{PAH}$ concentrations in the atmospheric $\mathrm{PM}_{2.5}$ of a business office area in Jinan, a heavily polluted city in China. Atmos. Res. 153: 276-285. doi: 10.1016/j.atmosres.2014.08.014.

Zikova, N., Hopke, P.K. and Ferro, A.R. (2017). Evaluation of new low-cost particle monitors for $\mathrm{PM}_{2.5}$ concentrations measurements. J. Aerosol Sci. 105: 24-34. doi: 10.1016/j. jaerosci.2016.11.010.

Received for review, January 29, 2019 Revised, August 29, 2019 Accepted, October 28, 2019 